\title{
Sticky silver nanoparticles and surface coatings of different textile fabrics stabilised by Muntingia calabura leaf extract
}

\author{
Achmad Syafiuddin $^{1,2} \cdot$ Mohamad Ali Fulazzaky $^{3,4}$ - Salmiati Salmiati ${ }^{1,2} \cdot$ Martin Roestamy $^{5}$. \\ Mohammad Fulazzaky ${ }^{6} \cdot$ Kasni Sumeru $^{7} \cdot$ Zulkifli Yusop $^{2}$
}

Received: 27 January 2020 / Accepted: 14 March 2020 / Published online: 20 March 2020

(c) Springer Nature Switzerland AG 2020

\begin{abstract}
Permanent deposition of silver nanoparticles (AgNPs) on the surface of textile fibre is essential for the long-term medical application of antibacterial textile products. This study aims to propose a new green method of using the pure leaf extract of Muntingia calabura and to create a permanent deposition of AgNPs on the fabric surfaces of cotton, polyester and nylon. The appearance of darker colour confirms the deposition of AgNPs on the fabric fibres. The capacity of water absorption decreased by $9.3,12.0$ and $23.0 \%$ and the textile density increased by $10.4,12.3$ and $5.9 \%$ were verified for the fabric fibres of cotton, polyester and nylon, respectively, after binding with AgNPs. The antibacterial activity of the cotton, polyester and nylon fabrics against Escherichia coli is better than that against Chromobacterium haemolyticum and then is better than that against Bacillus cereus. The results obtained using the new green method of processing heat treatment experiments by using the pure leaf extract to penetrate AgNPs inside the fabric fibres may contribute to advancing the application of antibacterial textile products for medical uses.
\end{abstract}

Keywords Antibacterial activity · Green method · Muntingia calabura · Pure leaf extract · Silver nanoparticles · Textile fibre

\section{Introduction}

Textiles are used worldwide in many traditional crafts such as sewing, quilting and embroidery for the numerous applications but can also serve as medium for growth and transportation of microorganisms. Several strategies have been proposed to improve the properties of textile fibres, including the modification of surface using synthetic organic compounds such as chitosan, triclosan, quaternary ammonium compounds, polybiguanides, N-halamines and silver nanoparticles (AgNPs) to produce an antibacterial textile surface [35]. Antibacterial textiles would be appropriate attire for many applications that require a strict cleaning schedule to maintain hygiene, health and

Electronic supplementary material The online version of this article (https://doi.org/10.1007/s42452-020-2534-5) contains supplementary material, which is available to authorized users.

$\triangle$ Mohamad Ali Fulazzaky, mohamad.ali.fulazzaky@tdtu.edu.vn | ${ }^{1}$ Department of Water and Environmental Engineering, School of Civil Engineering, Faculty of Engineering, Universiti Teknologi Malaysia (UTM), 81310 Skudai, Johor Bahru, Malaysia. ${ }^{2}$ Centre for Environmental Sustainability and Water Security, Faculty of Engineering, Universiti Teknologi Malaysia (UTM), 81310 Skudai, Johor Bahru, Malaysia. ${ }^{3}$ Department for Management of Science and Technology Development, Ton Duc Thang University, No.19, Nguyen Huu Tho Street, Tan Phong Ward, District 7, Ho Chi Minh City, Vietnam. ${ }^{4}$ Faculty of Environment and Labour Safety, Ton Duc Thang University, No.19, Nguyen Huu Tho Street, Tan Phong Ward, District 7, Ho Chi Minh City, Vietnam. ${ }^{5}$ School of Postgraduate Studies, Universitas Djuanda, Jalan Tol Ciawi No. 1, Ciawi, Bogor 16720, Indonesia. ${ }^{6}$ Department of Chemical Engineering, Faculty of Industrial Technology, Institut Teknologi Bandung, Jalan Ganesha No. 10, Bandung 40132, Indonesia. ${ }^{7}$ Department of Refrigeration and Air Conditioning, Politeknik Negeri Bandung, Gegerkalong Hilir Ciwaruga, Bandung 40012, Indonesia. 
happiness levels. Therefore, they are beneficially used for the medical clinics, hospitals, laboratories and health centres. The use of antibacterial AgNPs impregnated textiles in a long-term care ward may significantly reduce fever, antibiotic consumption and related treatment costs associated with the diagnosis and management of infection complications. The use of AgNPs has been reported effective as the treatment against burns, wounds and several bacterial infections and can either totally prevent, delay or otherwise reduce food spoilage $[19,43,56]$. The effectiveness of AgNPs has been investigated for their antimicrobial characteristics against a broad range of microorganisms including bacteria, yeast and fungi $[14,62]$. The application of AgNPs deposited on fabric fibre has gained a significant attention and has become more apparent in many medical applications of such as first-aid plasters, sterile surgical dressings, incision drapes, bandages and advance medical devices for the treatment of wounds $[37,53]$.

AgNPs deposition on the fabric surface or other material surfaces can be accomplished by using the various techniques such as immersion, layer-by-layer deposition of AgNPs films and sonochemical deposition [7, 40, 41, 47, 64]. Green synthesis of AgNPs to inhibit the pathogenic bacteria growth has been investigated using the turmeric extracts and the leave extracts of Camellia sinensis [2,38]. The deposition of AgNPs on the surface of textile fabrics such as cotton, wool, polyester, silk, cotton/polyester blend, regenerated cellulose and polyamide has been proposed to impart new functionality and improved performance [18]. However, the laundry of clothing and other textiles may release AgNPs from the fabric surface [7]. Therefore, the methods of coating the textile fabrics with AgNPs to remain a permanent deposition need to be continually revised and improved. The applications of binder, cross linkable polymer and crosslinking agents have been suggested for permanently binding AgNPs deposition on the fabric surface $[6,8,12,13,22,34,46]$. Nevertheless, the ways of attracting AgNPs potentially involve the hazardous chemicals and can be particularly harmful for the medical applications of using the antibacterial textiles to diminish new complications. It is suggested that new method of processing heat treatment experiments by using a pure leaf extract can penetrate AgNPs inside the fabric fibres and can avoid the release of AgNPs caused by washing of antibacterial textile fabrics. Even though the green synthesis of AgNPs stabilised using the Bridelia retusa leaf extract and making use of the Vigna mungo hull have been investigated to pave the way for eco-friendly utilisation $[60,61]$, the deposition of AgNPs onto the surface of different textile fabrics is still not fully understood. The objectives of this study are (1) to propose a new green method of using the pure leaf extract of Muntingia calabura for attracting AgNPs onto textile fibres and (2) to investigate the behaviour and antibacterial effect of AgNPs deposition on the different fabric surfaces of cotton, polyester and nylon without the addition of chemical substance.

\section{Materials and methods}

\subsection{Materials}

This study used the chemical reagent of $\mathrm{AgNO}_{3}$ originally delivered from QReC (Auckland, New Zealand). The leaves of $M$. calabura were collected from a location around the campus of Universiti Teknologi Malaysia, Johor Bahru, Malaysia. The plant of $M$. calabura has been authenticated by Dr. A. Balasubramanian with its authentication number of AUT/PUS/068 dated on 17 December 2014 [25]. The nylon membrane of $0.45 \mu \mathrm{m}$ purchased from Whatman Nylon Membranes-Sigma-Aldrich (St. Louis, MO, USA) was used as filter. The solutions were prepared using high-purity water with its resistivity of $18.2 \mathrm{M} \Omega \mathrm{cm}$ (at $25^{\circ} \mathrm{C}$ ), produced by the arium Water Purification Systems (Sartorius Malaysia Sdn Bhd, Kuala Lumpur, Malaysia). The textile fabrics of $100 \%$ cotton with its weight of $135 \mathrm{~g} /$ $\mathrm{m}^{2}, 100 \%$ polyester with its weight of $155 \mathrm{~g} / \mathrm{m}^{2}$ and $100 \%$ nylon with its weight of $102 \mathrm{~g} / \mathrm{m}^{2}$ were obtained from SBK Textile Trading, Johor Bahru, Malaysia. The culture media for the bacterial growth were prepared using the agar powder delivered from Oxoid Ltd (Nutrient Agar CM0003, Oxoid, Basingstoke, UK). Two bacteria of Escherichia coli (E. coli) and Bacillus cereus (B. cereus) were obtained from the Faculty of Biosciences and Medical Engineering, Universiti Teknologi Malaysia.

\subsection{Extraction of the Muntingia calabura leaves}

The sample of $M$. calabura leaves was washed three times with tap water and then three times with ultrapure water to remove the contaminations [31]. A $20 \mathrm{~g}$ of the leave sample was added into a beaker containing $200 \mathrm{~mL}$ of the ultrapure water and then heated at $250^{\circ} \mathrm{C}$ for $30 \mathrm{~min}$ and then cooled at room temperature. The extraction solution was filtered through with a $45 \mu \mathrm{m}$ nylon membrane using the DURAN ${ }^{\circ}$ filtering apparatus to obtain a pure leaf extract. The solution of pure leaf extract was stored in the fridge at $7{ }^{\circ} \mathrm{C}$ for the future uses.

\subsection{Deposition of AgNPs inside the textile fabric}

A solution of $0.15 \mathrm{M} \mathrm{AgNO}_{3}$ was prepared by dissolving $29.25 \mathrm{~g}$ of $\mathrm{AgNO}_{3}$ in $100 \mathrm{~mL}$ of ultrapure water. A textile fabric of $2 \times 2 \mathrm{~cm}$ was immersed in $5 \mathrm{~mL}$ of $0.15 \mathrm{M} \mathrm{AgNO}_{3}$ solution in a beaker of $50 \mathrm{~mL}$, stirring constantly for $2 \mathrm{~h}$, and then slowly added $5 \mathrm{~mL}$ of the pure leaf extract solution in 
a dark environment. The mix solution was then heated at $70^{\circ} \mathrm{C}$ for 10 min with constant magnetic stirring and then dried at $80^{\circ} \mathrm{C}$ for $10 \mathrm{~min}$.

\subsection{Measurements of water absorption and textile fabric density}

The absorption of water by a textile fabric is essential for the metabolic activity of bacteria and can be determined after $1 \mathrm{~h}$ immersion in distilled water. Therefore, the sample was weighed before and after immersion and then the absorption of water can be calculated using the equation [1] of:

$W=\frac{m_{\mathrm{a}}}{m_{\mathrm{o}}} \times 100 \%$

where $W$ is the water absorption by the textile fabric (in $\%), m_{\mathrm{a}}$ is the mass of textile fabric after the absorption of water (in $\mathrm{g}$ ), and $m_{\mathrm{o}}$ is the mass of textile fabric before the absorption of water (in g).

The density of textile fabric before and after the absorption of water can be determined using the equation of:

$D=\frac{m}{A}$

where $D$ is the textile fabric density (in $\mathrm{g} / \mathrm{m}^{2}$ ), $m$ is the mass of textile fabric (in $\mathrm{g}$ ), and $A$ is the area of textile fabric (in $m^{2}$ ).

\subsection{Bacterial identification}

This study used three bacterial strains to test the antibacterial activity of the textile fabrics after biding with AgNPs. Two bacterial strains of $E$. coli and $B$. cereus have been identified delivering from the Faculty of Biosciences and Medical Engineering, Universiti Teknologi Malaysia. One strain of bacteria was isolated from the wastewater collected from a domestic wastewater treatment plant managed by Indah Water Konsortium Sdn Bhd located at Taman Universiti, Johor Bahru, Malaysia. The Polymerase Chain Reaction (PCR) was used to amplify the specific region of the 16s rRNA gene of unknown bacteria and to generate the DNA target sequence of interest for the identification of bacterial strains found in the wastewater environment [9]. The strain of Chromobacterium haemolyticum (C. haemolyticum) was identified using the basic local alignment search tool (BLAST) carried out by the First BASE Laboratories Sdn Bhd, Selangor, Malaysia.

\subsection{Characterisation of the textile fabric surfaces}

The characterisation of three textile fabrics of cotton, polyester, and nylon was carried out for each sample with three replicates, without and with binded AgNPs. The surface morphology of textile fabric was examined using the Field Emission Scanning Electron Microscopy (FESEM) of Zeiss SUPRA 35VP model, which was operated at $5 \mathrm{kV}$. The distribution of AgNPs and other elements on the surface of textile fabric was examined using the Scanning Electron Microscopy with Energy Dispersive X-ray Spectroscopy (SEM-EDX) of Hitachi S-3400N model, operated at $15 \mathrm{kV}$. For the purpose of this work, the SEM-EDX was equipped with the Bruker QUANTAX 200 software.

\subsection{Inhibition zone test}

A standardised approach is needed to assess AgNPs toxicity to both Gram-negative and Gram-positive bacteria [33]. The culture media of Nutrient Agar (NA) for bacterial growth were prepared by adding $20 \mathrm{~g}$ of agar powder in $1 \mathrm{~L}$ of ultrapure water. The NA along with petri dishes was sterilised by heating in an autoclave. Approximately $25 \mathrm{~mL}$ of the liquefied NA was poured into a petri dish and then spread $0.1 \mathrm{~mL}$ of the liquid bacterial culture on the NA surface. A textile fabric after binded AgNPs was put on the petri dish and then placed in an oven at $37^{\circ} \mathrm{C}$ for $5 \mathrm{~d}$. Clear zone surrounding the bacterial growth was measured for quantifying the zone of inhibition. The test of textile fabric without binded AgNPs was performed as a control test, using the same procedure.

\section{Results and discussion}

\subsection{Results}

\subsubsection{Colour transformation of the textile fabrics}

The results (Figs. 1, 2, 3) of changed colour may indicate the adsoption of AgNPs on the surface of textile fabric. The transformation of colour from red (see Fig. 1a) to black (see Fig. 1b), from tan (see Fig. 2a) to black (see Fig. 2b), and from orange (see Fig. 3a) to black (see Fig. 3b) was verified for textile fibre of $100 \%$ cotton, $100 \%$ polyester, and $100 \%$ nylon, respectively. The appearance of darker colour may confirm the adsorption of AgNPs onto the fabric surface of cotton $[4,44]$. The fabric surface of wool treated with AgNPs can enhance the antibacterial properties [20].

\subsubsection{Water absorption and textile fabric density}

The presence of AgNPs deposition on the surface of textile fabric can decrease the capacity of water absorption. The results of water absorption measurement show that (1) the capacity of water absorption for cotton woven fabric decreases by $9.3 \%$, (2) the capacity of water absorption for polyester woven fabric decreases by 
Fig. 1 Transformation of colour on the surface of textile fabric, with a $100 \%$ cotton before binded AgNPs and b $100 \%$ cotton after binded AgNPs
Fig. 2 Transformation of colour on the surface of textile fabric, with a $100 \%$ polyester before binded AgNPs and b $100 \%$ polyester after binded AgNPs

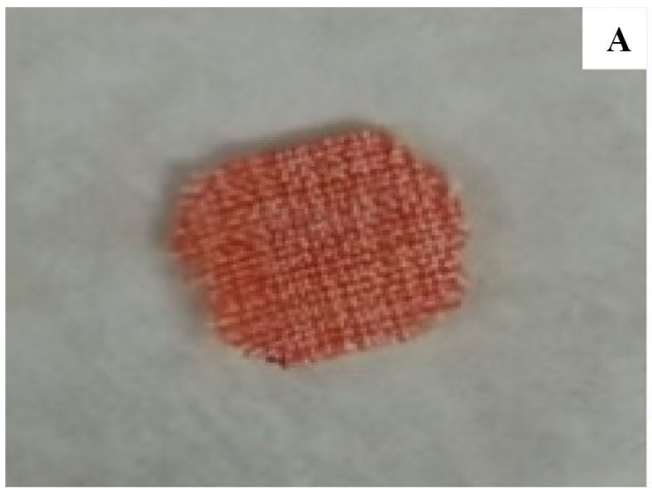

A

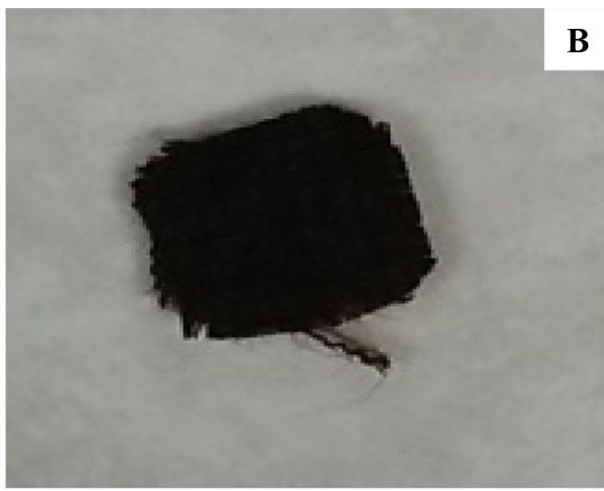

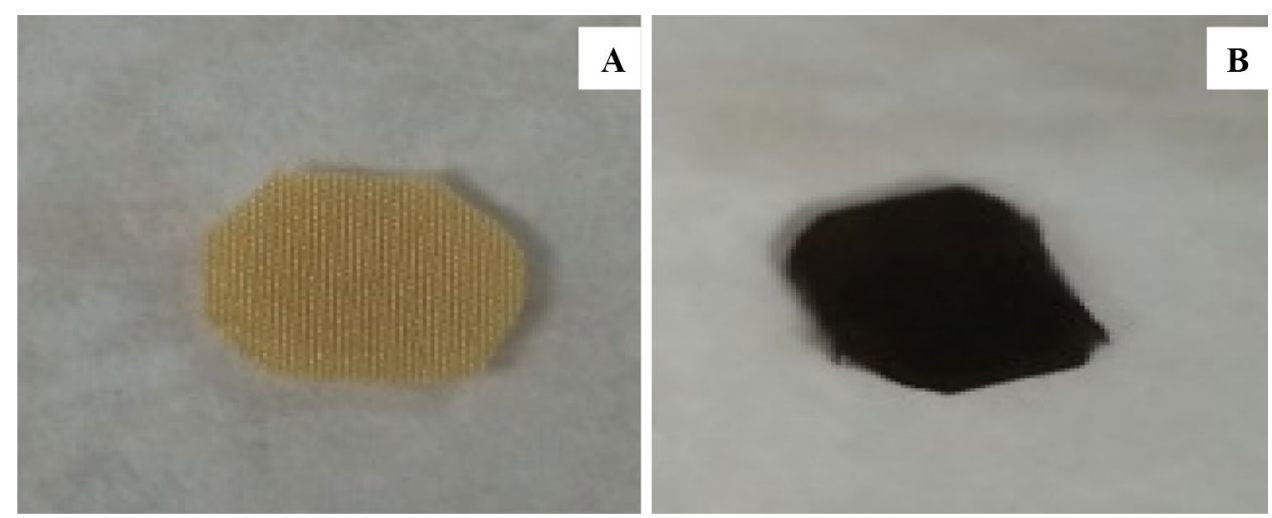

Fig. 3 Transformation of colour on the surface of textile fabric, with a $100 \%$ nylon before binded AgNPs and b $100 \%$ nylon after binded AgNPs
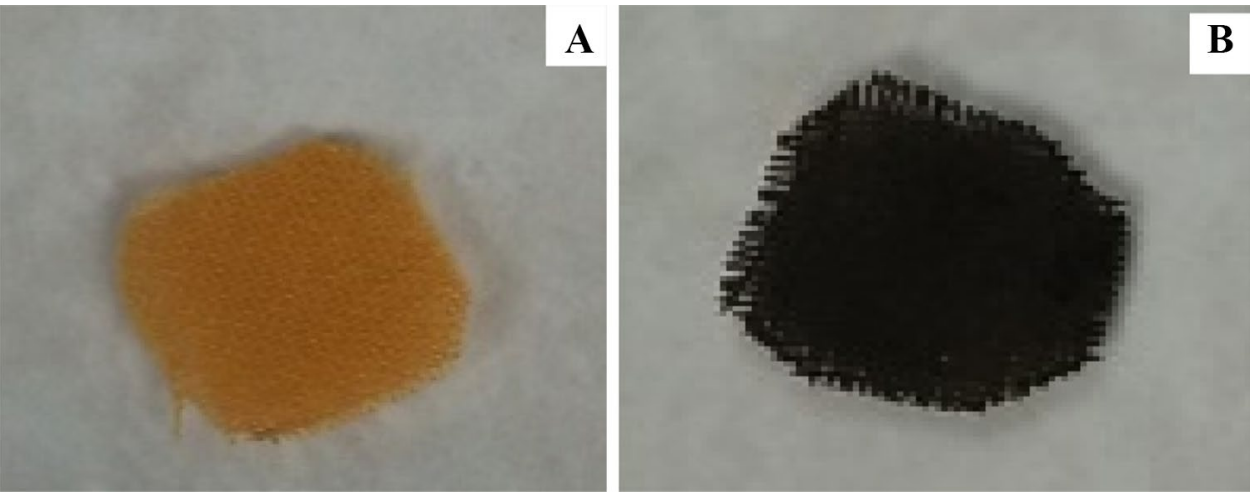

$12.0 \%$, and (3) the capacity of water absorption for nylon woven fabric decreases by $23.0 \%$. A decresae in the water absorption capacity of AgNPs embedded nylon fibres is greater than that of AgNPs embedded polyester fibres and then is greater than that of AgNPs embedded cotton fibres. Density of textile fabric increases with AgNPs deposited on its surface. The results of density measurement show that (1) the density of cotton woven fabric increases by $10.4 \%$ from 135 to $149 \mathrm{~g} / \mathrm{m}^{2}$, (2) the density of polyester woven fabric increases by $12.3 \%$ from 155 to $174 \mathrm{~g} / \mathrm{m}^{2}$, and (3) the density of nylon woven fabric increases by $5.9 \%$ from 102 to $108 \mathrm{~g} / \mathrm{m}^{2}$.

\subsubsection{Surface morphology of the textile fabrics}

The surface morphology of three textile fabrics was observed using the FESEM analysis before and after binded AgNPs, as shown in Figs. 4, 5 and 6. The scanning of cotton surface morphology (Fig. 4a, b) shows that (1) the FESEM image of Fig. $4 a$ for pristine cotton fabric has a structure of the smooth longitudinal fibrillar cotton fibers without contaminant particles and (2) the FESEM image (Fig. 4b) of micro-rough surface structure indicates the AgNPs deposited on the cotton fabric surface. The deposition of AgNPs on the cotton fabric surface becomes clearly apparent in 

textile fabric surface, with a $100 \%$ cotton before binded AgNPs and b $100 \%$ cotton after binded AgNPs at $30 \mathrm{k}$ magnification
Fig. 4 FESEM image of the
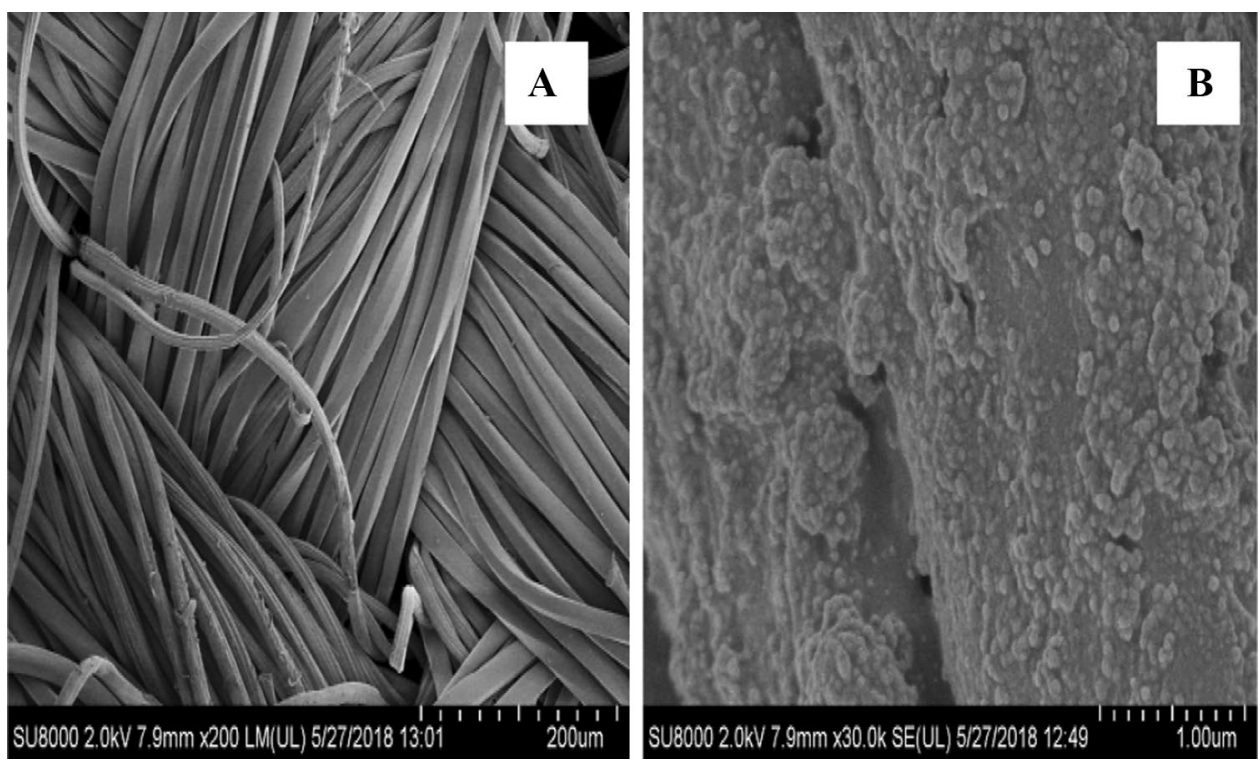

Fig. 5 FESEM image of the textile fabric surface, with a $100 \%$ polyester before binded AgNPs and b $100 \%$ polyester after binded AgNPs at $30 \mathrm{k}$ magnification
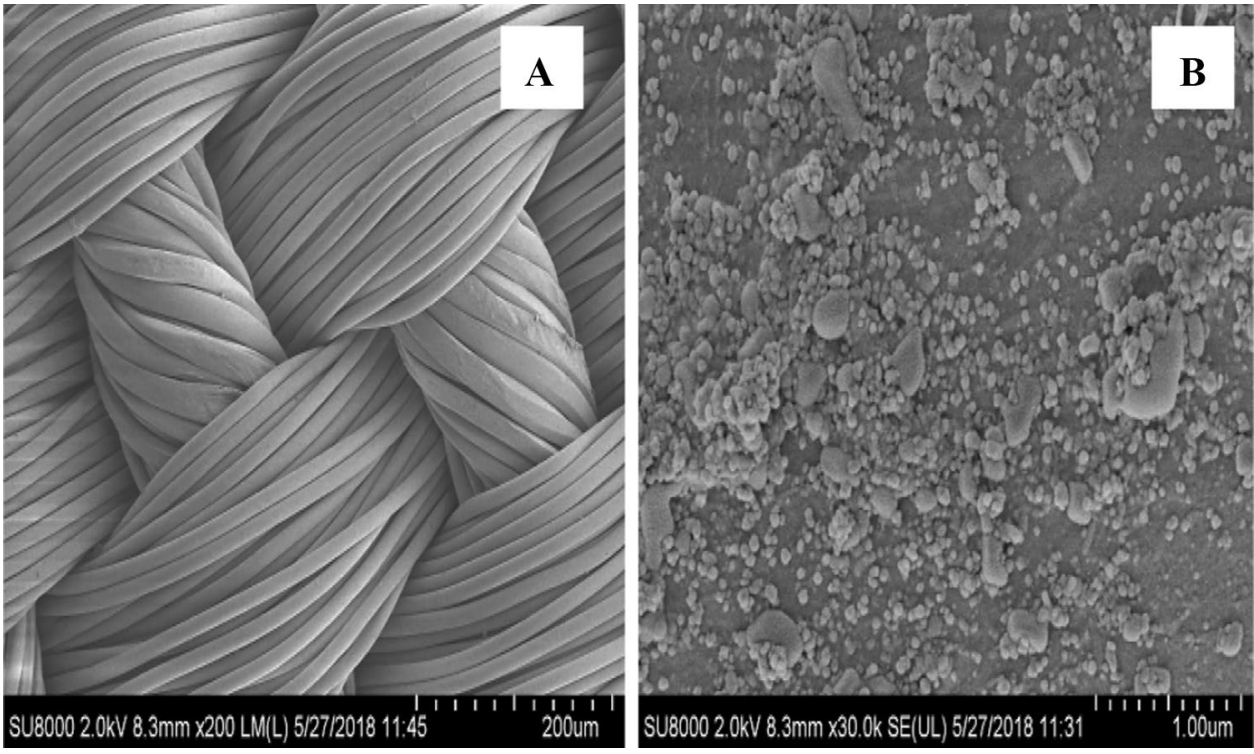

the FESEM image of Fig. $4 \mathrm{~b}$ with $30 \mathrm{k}$ magnification, which shows the AgNPs deposition almost entirely covered cotton fabric surface. The scanning of polyester surface morphology (Fig. 5a, b) shows that (1) it is not apparent AgNPs contamination observed on the FESEM image of Fig. 5a for pristine polyester fabric and (2) the FESEM image of Fig. $5 \mathrm{~b}$ with appeared micro-rough surface structure may indicate the AgNPs deposited on the polyester fabric surface. The deposition of AgNPs on the polyester fabric surface in the forms of agglomerates and single particles may reveal the polyester fabric surface almost entirely covered by the AgNPs deposition, as can be observed in the FESEM image of Fig. $5 \mathrm{~b}$ with $30 \mathrm{k}$ magnification. It can be seen from the scanning of nylon surface morphology (see Fig. 6a, b) that (1) the FESEM image of Fig. 6a has a structure of smooth longitudinal fibrillar nylon fibres without any contaminant particles on the surface of pristine nylon fabric and (2) the FESEM image of Fig. 6b indicates the AgNPs deposition on nylon fabric surface with the appearance of micro-rough structure. The deposition of AgNPs on the nylon fabric surface is clearly apparent at $30 \mathrm{k}$ magnification, which shows almost entirely covered by AgNPs deposition (see Fig. 6b).

\subsubsection{AgNPs distribution and elemental composition}

In spite of the X-ray diffraction technique can be used to analyse structural features of the textile fabrics and the Fourier-transform infrared spectroscopy can be used to detect structural variation of semicrystalline polymers on the surface of textile fabric before and after binded 
Fig. 6 FESEM image of the textile fabric surface, with a $100 \%$ nylon before binded AgNPs and $\mathbf{b} 100 \%$ nylon after binded AgNPs at $30 \mathrm{k}$ magnification
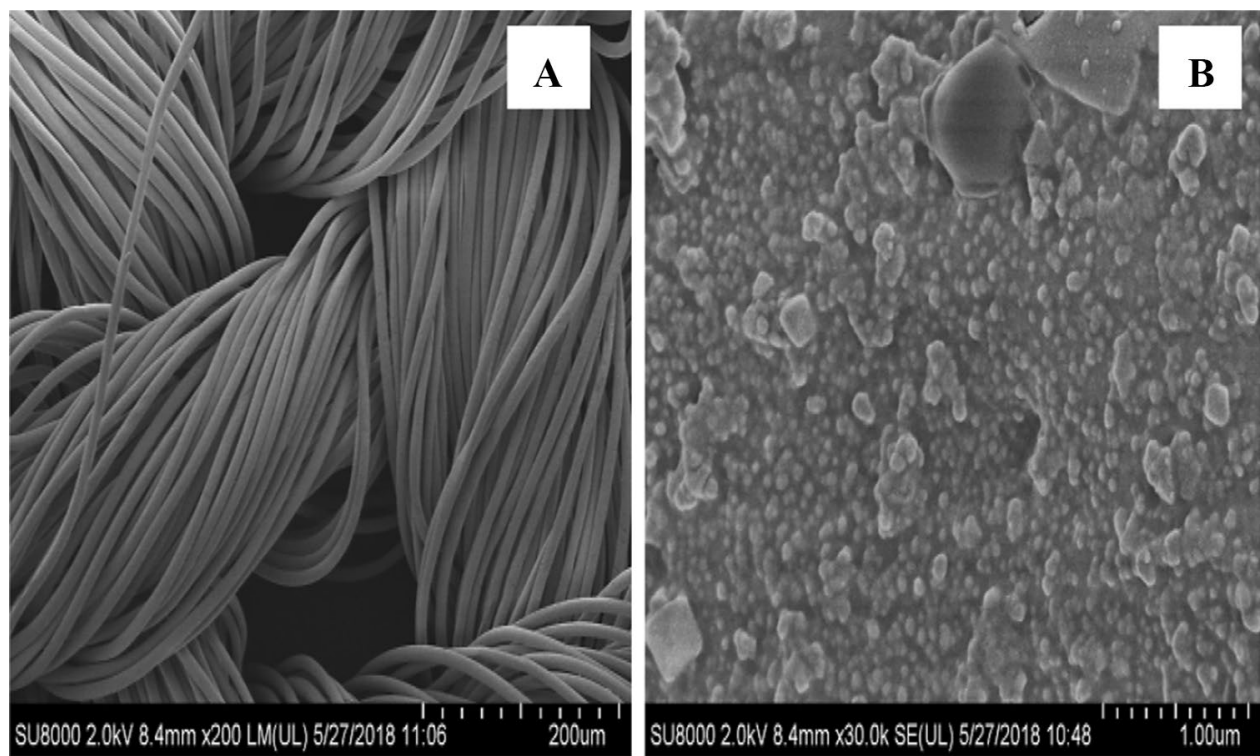

AgNPs, this study only focuses on the investigation of morphological change and elemental composition on three textile fabric surfaces. The results (Supplementary materials: Figs. IA, C, E) of morphological change investigated by the SEM-EDX technique show the AgNPs distribution on the fabric surfaces of cotton, polyester and nylon. The agglomerates of AgNPs cover some parts of the cotton fabric surface in spite of the unequal distribution of AgNPs relates more with deposition amongst smaller groups of AgNPs precipitates (see Supplementary materials: Fig. IA). The uniform distribution of AgNPs appears on the surface of polyester fabric there is not apparent the agglomerates of AgNPs (see Supplementary materials: Fig. IC). The presence of AgNPs on the surface of nylon fabric can be seen in form of the agglomerates while the very small crystalline AgNPs are dispersed and distributed over half of the nylon fabric surface (see Supplementary materials: Fig. IE).

The SEM-EDX spectrum analysis of elemental composition can verify the AgNPs suspension on the fabric surfaces of cotton, polyester and nylon (see Supplementary materials: Figs. IB, D, F). The SEM-EDX spectrum recorded showing a peak approximately near $3 \mathrm{keV}$ confirms the presence of silver [59]. The percent compositions of carbon, oxygen, silver and nitrogen on the cotton fabric surface are as high as $46.3,26.8,24.8$ and $2.0 \%$, respectively (see Supplementary materials: Fig. IB). The percent compositions of carbon, oxygen, silver and nitrogen on the polyester fabric surface are as high as 52.7, 29.7, 13.4 and $4.2 \%$, respectively (see Supplementary materials: Fig. ID). The percent compositions of carbon, oxygen, silver and nitrogen on the nylon fabric surface are as high as 42.1, 27.8, 23.4 and $6.7 \%$, respectively (see Supplementary materials: Fig. IF).

\subsubsection{Antibacterial properties of the textile fabrics}

Antibacterial properties of the cotton, polyester, and nylon fabric surfaces after binded AgNPs were examined using three different bacterial strains of E. coli, B. cereus, and C. haemolyticum. The results (Supplementary materials: Fig. Il; see Table 1) of antibacterial examination show that the inhibition zones are all not apparent on the surfaces of cotton, polyester, and nylon fabric before binded AgNPs (see Supplementary materials: Figs. IIA, E, I). The inhibition zones for Gram-negative bacteria $E$. coli after binded AgNPs are all clearly apparent on the surfaces of cotton, polyester, and nylon fabric with the large zones of $6.33 \pm 2.08,3.33 \pm 0.58$, and $4.33 \pm 0.58 \mathrm{~mm}$, respectively (see Supplementary materials: Figs. IIB, C, D). The inhibition zones for new isolated Gram-negative bacteria C. haemolyticum after binded AgNPs are all clearly apparent on the surfaces of cotton, polyester and nylon fabric with the large zones of $5.67 \pm 0.58,2.33 \pm 0.58$ and $2.00 \pm 1.00 \mathrm{~mm}$, respectively (see Supplementary materials: Figs. IIF, G, H). The inhibition zones for Gram-positive bacteria B. cereus after binded AgNPs are all clearly apparent on the surfaces of cotton, polyester, and nylon fabric with the large zones

Table 1 Zone of inhibition for three tested bacterial strains of $E$. coli, B. cereus and C. haemolyticum on fabric surfaces of cotton, polyester, and nylon after binded AgNPs

\begin{tabular}{llll}
\hline Bacterial strain & \multicolumn{3}{l}{ Zone of inhibition $(\mathrm{mm})$} \\
\cline { 2 - 4 } & Cotton fabric & Polyester fabric & Nylon fabric \\
\hline E. coli & $6.33 \pm 2.08$ & $3.33 \pm 0.58$ & $4.33 \pm 0.58$ \\
B. cereus & $2.00 \pm 0.00$ & $2.33 \pm 0.58$ & $2.33 \pm 0.58$ \\
C. haemolyticum & $5.67 \pm 0.58$ & $2.33 \pm 0.58$ & $2.00 \pm 1.00$ \\
\hline
\end{tabular}


of $2.00 \pm 0.00,2.33 \pm 0.58$ and $2.33 \pm 0.58 \mathrm{~mm}$, respectively (see Supplementary materials: Figs. IIJ, K, L).

\subsection{Discussion}

In spite of the AgNPs exhibits yellowish brown colour caused by the excitation of surface plasmon vibrations $[20,21]$, the effect of interaction between pure leaf extract of $M$. calabura and AgNPs on the property of fabric surfaces may alter the colour of AgNPs deposition to darker (see Figs. 1, 2, 3). This would be due to AgNPs excites the resonance effect of light trapping when pairing with dielectric materials of cotton, polyester, and nylon [66]. The sensitivity of plasmon resonance to size, shape, and metal composition may cause different sizes and forms in the deposition of AgNPs [26]. The examinations of surface morphology, AgNPs distribution, element composition, and antibacterial property of AgNPs embedded textile fibres are important for intended uses of the textile fabrics [35]. A new green method using a pure leaf extract can reduce environmental impact of smart textiles for state-of-the-art products and future developments [22]. The advantage of mixing AgNPs with leaf extract of $M$. calabura can penetrate AgNPs inside the fabric fibres to ensure a permanent colour and antibacterial property of the textile fabrics. In spite of the extract of $M$. calabura contains many flavanoids as bioreductor compounds [65], the transformation of $\mathrm{Ag}^{+}$to $\mathrm{Ag}_{2} \mathrm{O}$ as shown with a dark colour may occur by heating the solution containing of $\mathrm{AgNO}_{3}$, M. calabura extract, and textile fabric at $70^{\circ} \mathrm{C}$ for $10 \mathrm{~min}$ and can be described by the chemical reaction: $2 \mathrm{Ag}^{+}+2 \mathrm{OH}^{-} \rightarrow \mathrm{Ag}_{2} \mathrm{O}+\mathrm{H}_{2} \mathrm{O}$ [55]. This study suggested that the future experiment would be necessary to perform XRD or XPS analysis of the $\mathrm{Ag}_{2} \mathrm{O}$ formation on the surface of textile fabric to verify the real state of silver in the AgNPs.

The water absorption property of a textile fabric refers to the capacity of fibre to retain a level of moisture, which might be useful in facilitating the growth of bacteria. A modification of fibre surface by embedding AgNPs can reduce the capacity of water absorption due to the deposition of AgNPs may alter the porosity, capillary pressure, and pore size distribution [29]. Hydrophobic property of AgNPs can act as a barrier to reduce contact angle between fibre and water. The capillary penetration of AgNPs on the cotton fibre can reduce the capacity of water absorption by $9.3 \%$. The deposition of AgNPs on the surface of polyester fibre can reduce the absorption of water by $12.0 \%$. This may relate to a simultaneous capillary penetration and imbibition by fibres. The deposition of AgNPs on the surface of nylon fibre can reduce the water absorption by $23.0 \%$. This can be related to simultaneous capillary penetration, imbibition by fibers, and AgNPs deposited on the surface of fibers [23].
The measurement of textile fabric density helps explain the thickness of AgNPs coated on the fibre surface. The density of cotton fabric increases by $10.4 \%$ from 135 to $149 \mathrm{~g} / \mathrm{m}^{2}$ after the deposition of AgNPs as a result of forming a hierarchical structure [49]. The density of polyester fabric increases by $12.3 \%$ from 155 to $174 \mathrm{~g} / \mathrm{m}^{2}$ there is due to the uniform distribution of AgNPs on the surface of fibre can easily increase the thickness of film layer with increasing of the AgNPs deposition on the polyester fabric [15]. The density of nylon fabric only increases by $5.9 \%$ from 102 to $108 \mathrm{~g} / \mathrm{m}^{2}$ due to the layer of the AgNPs thin film deposites on the surface of nylon fabric; very small crystalline AgNPs may distribute over half of the nylon fibre surface [7].

The surface morphology of the pristine cotton, polyester, and nylon fabrics shows a smooth longitudinal structure of the textile fibres before binded AgNPs due to the contamination of AgNPs does not appear on the fabric surface (see Figs. 4a, 5a, 6a). A technological intervention related to the application of AgNPs has an immense use in the future [57]. The accurrance (see Figs. 4b, 5b, 6b) of rough fibre surface can be observed after binding with AgNPs because of the deposition of AgNPs may make a modification of the surface morphology of the textile fabrics $[7,49]$. The formation of single particles and agglomerates in different sizes of the microparticles can be observed in Figs. $4 \mathrm{~b}, 5 \mathrm{~b}$ and $6 \mathrm{~b}$ due to each fabric surface has a unique interaction between AgNPs and textile fibre [32].

Mapping the spatial distribution of AgNPs on the surface of textile fabric can be done based on the SEM-EDX investigation. A heat treatment experiment of using the leaf extract of M. calabura is able to bind AgNPs with fabric surface in typical form, size, orientation, and the intensity of interaction with fibre, depending on the textile fabric type (see Supplementary materials: Figs. IA, C, E). The agglomerates of AgNPs occurred at some parts of the cotton fabric surface (see Supplementary materials: Fig. IA) are due to soft and fluffy staple fibre of cotton has higher flexibility and can agglomerate AgNPs more effectively (Jones, [17]. The uniform distribution of AgNPs observed on the polyester fabric surface as shown in Fig. IC could be due to more condensation polymer of polyester, which contain ester functional group in their main chain, can interact with AgNPs to disperse microparticles uniformly [16]. This is mainly affected by its organic matter content [10]. The rare agglomerates of AgNPs and very small AgNPs crystalline observed on the nylon fabric surface as shown in Fig. IE could be due to hydrophilic material of nylon can seep water into the fibres more easily [39]. The use of polyester fabric with AgNPs uniformly distributed on the fibre surface as antibacterial textile could be better than that of cotton and nylon fabrics due to the maximum entropy can 
achieve a good performance of the structural reliability when the probability distribution is uniform [36].

The element composition on the surface of the textile fabrics was analysed based on the SEM-EDX spectra (see Supplementary materials: Figs. IB, D, F). The elemental analysis confirms the presence of $\mathrm{Ag}^{+}$ions due to the SEM-EDX images display a spectral peak at $3 \mathrm{keV}$ corresponding to metallic silver $[45,63]$. The percent compositions of carbon, oxygen, silver, and nitrogen on the fabric surfaces are different, depending on the types of textile fibre [48]. The silver composition of $24.8 \%$ on the cotton fibre is higher than that of $23.4 \%$ on the nylon fibre and then is higher than that of $13.4 \%$ on the polyester fibre (see Supplementary materials: Figs. IB, D, F), while the size of AgNPs agglomerates appeared on the surface of cotton fibre is greater than that appeared on the surface of nylon fibre and then is greater than that appeared on the surface of polyester fibre (see Supplementary materials: Figs. IA, $C, E)$. This means that the composition of silver on fabric surface may contribute to the size of AgNPs agglomerates.

The antibacterial properties of cotton, polyester, and nylon fabrics were verified against three bacteria of $E$. coli, $B$. cereus, and C. haemolyticum without and with changed fabric surface after binded AgNPs. The results (Supplementary materials: Fig. II; see Table 1) of inhibition zone show that the antibacterial activity of cotton, polyester, and nylon fabrics against $E$. coli is better than that against C. haemolyticum and then is better than that against $B$. cereus. Therefore, the diameters of inhibition zone that represent an effect of AgNPs on the E. coli growth are all greater than those on the $B$. cereus growth and then are greater than those on the $C$. haemolyticum growth on the fabric surfaces of cotton, polyester and nylon (see Table 1). The inhibition zone diameter of $6.33 \pm 2.08 \mathrm{~mm}$ against Gram-negative bacteria E. coli [58] is greather than that of $5.67 \pm 0.58 \mathrm{~mm}$ against Gram-negative bacteria C. haemolyticum [3] and then is greater than that of $2.00 \pm 0.00 \mathrm{~mm}$ against Gram-positive bacteria B. cereus [5]. This may be due to Gram-positive bacteria have despite a lack of outer membrane but are surrounded by layers of peptidoglycan many times thicker than those found in Gram-negatives [50]. The layers of peptidoglycan help protect the bacterial cells of $B$. cereus from environmental stress of diffusing AgNPs and help preserve its cell morphology from the disturbance of AgNPs deposition. Antibacterial activity and acting mechanism of AgNPs against $E$. coli could be due to the deposition of AgNPs on the textile fabric surfaces can damage the structure of bacterial cell membrane and thus depress the activity of the membranous enzymes, which cause the E. coli bacteria to die eventually [28]. Since the activity of Gram-negative bacteria of E. coli and C. haemolyticum depends on an enzyme to metabolise oxygen to maintain their live, the deposition of AgNPs on fabric surface can interfere with the effectiveness of enzyme and disables the uptake of oxygen, which may cause the bacteria of E. coli and C. haemolyticum to die [52]. The adhesion of AgNPs to bacterial walls can penetrate the membrane and peptidoglycan layers of the Gram-negative bacteria of $E$. coli and C. haemolyticum. The bacterial cells can release antimicrobial $\mathrm{Ag}^{+}$ions from AgNPs inside the cells to interact with respiratory chain and to bind the thiol group of enzymes and amino acids [11, 30, 42, 51, 54]. The interaction of $\mathrm{Ag}^{+}$with thiol group of proteins and essential enzymes in the cellular respiratory chain can generate the reactive oxygen species. This may lead to the inactivation of the proteins. The process of extracting energy from the oxidation of organic compounds to produce $\mathrm{CO}_{2}$ and $\mathrm{H}_{2} \mathrm{O}$ doesn't occur in the Gram-negative bacteria of $E$. coli and C. haemolyticum $[8,24,27]$.

\section{Conclusions}

This study proposed a new green method of using the pure leaf extract of $M$. calabura to bind AgNPs on the fabric surfaces of cotton, polyester, and nylon. The effect of interaction between $M$. calabura leaf extract and AgNPs on the property of fabric surface can alter the colour of AgNPs deposition from naturally lighter to darker colour. The deposition of AgNPs on fabric surface can reduce the water absorption leading to increase the density of textile fabric. The AgNPs deposition can modify the surface morphology of textile fabric by the formation of single particles and agglomerates of different sizes of the microparticles. The uniform distribution of AgNPs on polyester fabric surface achieves a good performance of structural reliability. The antibacterial property of the cotton, polyester, and nylon fabrics after binded AgNPs against Gram-negative bacteria of E. coli and C. haemolyticum could be better than Gram-positive bacteria $B$. cereus. The result findings of antibacterial effect of AgNPs deposition on the textile fabric surfaces contribute to many medical applications of the textile fabrics related to both Gram-positive and Gram-negative bacteria strains.

Acknowledgements The authors gratefully acknowledge financial support from (1) the Malaysian Ministry of Higher Education for Fundamental Research Grant Scheme No. R.J130000.7809.4F619, (2) the Universiti Teknologi Malaysia for Research University Grant No. Q.J130000.2522.14H40, and (3) the Ton Duc Thang University for Contract No. 551/2019/TĐT-HĐLV-NCV.

Data availability The raw/processed data required to reproduce these findings cannot be shared at this time as the data also forms part of an ongoing study. 


\section{Compliance with ethical standards}

Conflict of interest All the authors declare no conflict of interest.

\section{References}

1. Alay S (2010) An investigation of knitted fabric performances obtained from different natural and regenerated fibres. J Eng Sci Des 1:91-95

2. Alsammarraie FK, Wang W, Zhou P, Mustapha A, Lin M (2018) Green synthesis of silver nanoparticles using turmeric extracts and investigation of their antibacterial activities. Colloids Surf B Biointerfaces 171:398-405

3. Bajaj A, Kumar A, Yadav S, Kaur G, Bala M, Singh NK, Kumar RM, Manickam N, Mayilraj S (2016) Isolation and characterization of a novel Gram-negative bacterium Chromobacterium alkanivorans sp. nov., strain IITR-71T degrading halogenated alkanes. Int J Syst Evol Microbiol 66:5228-5235

4. Ballottin D, Fulaz S, Cabrini F, Tsukamoto J, Durán N, Alves OL, Tasic L (2017) Antimicrobial textiles: biogenic silver nanoparticles against Candida and Xanthomonas. Mater Sci Eng C Mater Biol Appl 75:582-589

5. Bottone EJ (2010) Bacillus cereus, a volatile human pathogen. Clin Microbiol Rev 23:382-398

6. Dastjerdi R, Montazer M (2010) A review on the application of inorganic nano-structured materials in the modification of textiles: focus on anti-microbial properties. Colloids Surf B Biointerfaces 79:5-18

7. Deng X, Nikiforov AY, Coenye T, Cools P, Aziz G, Morent R, De Geyter N, Leys C (2015) Antimicrobial nano-silver non-woven polyethylene terephthalate fabric via an atmospheric pressure plasma deposition process. Sci Rep 5:10138

8. El-Rafie M, Mohamed A, Shaheen TI, Hebeish A (2010) Antimicrobial effect of silver nanoparticles produced by fungal process on cotton fabrics. Carbohydr Polym 80:779-782

9. Fulazzaky MA, Abdullah S, Salim MR (2015) Fundamentals of mass transfer and kinetics for biosorption of oil and grease from agro-food industrial effluent by Serratia marcescens SA30. RSC Adv 5:104666-104673

10. González-Fuenzalida RA, Sanjuan-Navarro L, Moliner-Martínez Y, Campíns-Falcó P (2018) Quantitative study of the capture of silver nanoparticles by several kinds of soils. Sci Total Environ 630:1226-1236

11. Hsueh Y-H, Lin K-S, Ke W-J, Hsieh C-T, Chiang C-L, Tzou D-Y, Liu S-T (2015) The antimicrobial properties of silver nanoparticles in Bacillus subtilis are mediated by released $\mathrm{Ag}^{+}$ions. PLoS ONE 10:e0144306

12. Ibrahim NA, Aly AA, Eid BM, Fahmy HM (2018) Green approach for multifunctionalization of cellulosecontaining fabrics. Fibers Polym 19:2298-2306

13. Ibrahim NA, Eid BM, Abdel-Aziz MS (2017) Effect of plasma superficial treatments on antibacterial functionalization and coloration of cellulosic fabrics. Appl Surf Sci 392:1126-1133

14. Jaidev LR, Narasimha G (2010) Fungal mediated biosynthesis of silver nanoparticles, characterization and antimicrobial activity. Colloids Surf B Biointerfaces 81:430-433

15. Jalili S, Hajakbari F, Hojabri A (2018) Effect of silver thickness on structural, optical and morphological properties of nanocrystalline $\mathrm{Ag} / \mathrm{NiO}$ thin films. J Theor Appl Phys 12:15-22

16. Javadi A, Zhao J, Cao C, Pozuelo M, Yang Y, Hwang I, Lin TC, Li X (2017) Stretching micro metal particles into uniformly dispersed and sized nanoparticles in polymer. Sci Rep 7:7098
17. Jones AG (1993) Particle breakage, abnormal growth and agglomeration during industrial crystallization. Anal Proc 30:456-457

18. Joshi M, Bhattacharyya A (2011) Nanotechnology—a new route to high-performance functional textiles. Text Prog 43:155-233

19. Kebede MA, Imae T, Wu C-M, Cheng K-B (2017) Cellulose fibers functionalized by metal nanoparticles stabilized in dendrimer for formaldehyde decomposition and antimicrobial activity. Chem Eng J 311:340-347

20. Kelly FM, Johnston JH (2011) Colored and functional silver nanoparticle-wool fiber composites. ACS Appl Mater Interfaces 3:1083-1092

21. Khan Z, Hussain Jl, Hashmi AA, AL-Thabaiti SA (2017) Preparation and characterization of silver nanoparticles using aniline. Arab J Chem 10:S1506-S1511

22. Kim D-Y, Saratale RG, Shinde S, Syed A, Ameen F, Ghodake G (2018) Green synthesis of silver nanoparticles using Laminaria japonica extract: characterization and seedling growth assessment. J Clean Prod 172:2910-2918

23. Kissa E (1996) Wetting and wicking. Text Res J 66:660-668

24. Korshed P, Li L, Liu Z, Wang T (2016) The molecular mechanisms of the antibacterial effect of picosecond laser generated silver nanoparticles and their toxicity to human cells. PLoS ONE 11:e0160078

25. Krishnaveni $M$, Ragina banu $C$, Krishna kumari G, Kalaivani M (2015) GCMS/MS analysis of Muntingia calabura steam and its antimicrobial effect. World J Pharm Pharm Sci 4:812-817

26. Lee KS, El-Sayed MA (2006) Gold and silver nanoparticles in sensing and imaging: sensitivity of plasmon response to size, shape, and metal composition. J Phys Chem B 110:19220-19225

27. Li Q, Mahendra S, Lyon DY, Brunet L, Liga MV, Li D, Alvarez PJ (2008) Antimicrobial nanomaterials for water disinfection and microbial control: potential applications and implications. Water Res 42:4591-4602

28. Li WR, Xie XB, Shi QS, Zeng HY, Ou-Yang YS, Chen YB (2010) Antibacterial activity and mechanism of silver nanoparticles on Escherichia coli. Appl Microbiol Biotechnol 85:1115-1122

29. Lin S, Cheng Y, Bobcombe Y, Jones KL, Liu J, Wiesner MR (2011) Deposition of silver nanoparticles in geochemically heterogeneous porous media: predicting affinity from surface composition analysis. Environ Sci Technol 45:5209-5215

30. Long Y-M, Hu L-G, Yan X-T, Zhao X-C, Zhou Q-F, Cai Y, Jiang G-B (2017) Surface ligand controls silver ion release of nanosilver and its antibacterial activity against Escherichia coli. Int J Nanomed 12:3193-3206

31. Mahmood ND, Nasir NLM, Rofiee MS, Tohid SFM, Ching SM, Teh LK, Salleh MZ, Zakaria ZA (2014) Muntingia calabura: a review of its traditional uses, chemical properties, and pharmacological observations. Pharm Biol 52:1598-1623

32. Mahmud S, Sultana MZ, Pervez MN, Habib MA, Liu H-H (2017) Surface functionalization of "Rajshahi Silk" using green silver nanoparticles. Fibers 5:35

33. McGillicuddy E, Murray I, Kavanagh S, Morrison L, Fogarty A, Cormican M, Dockery P, Prendergast M, Rowan N, Morris D (2017) Silver nanoparticles in the environment: sources, detection and ecotoxicology. Sci Total Environ 575:231-246

34. Montazer M, Alimohammadi F, Shamei A, Rahimi MK (2012) Durable antibacterial and cross-linking cotton with colloidal silver nanoparticles and butane tetracarboxylic acid without yellowing. Colloids Surf B Biointerfaces 89:196-202

35. Morais DS, Guedes RM, Lopes MA (2016) Antimicrobial approaches for textiles: from research to market. Materials 9:498

36. Muñoz-Cobo J-L, Mendizábal R, Miquel A, Berna C, Escrivá A (2017) Use of the principles of maximum entropy and maximum relative entropy for the determination of uncertain parameter distributions in engineering applications. Entropy 19:486 
37. Nikiforov AY, Deng X, Onyshchenko I, Vujosevic D, Vuksanovic V, Cvelbar U, De Geyter N, Morent R, Leys C (2016) Atmospheric pressure plasma deposition of antimicrobial coatings on nonwoven textiles. Eur Phys J Appl Phys 75:24710

38. Onitsuka S, Hamada T, Okamura H (2019) Preparation of antimicrobial gold and silver nanoparticles from tea leaf extracts. Colloids Surf B Biointerfaces 173:242-248

39. Ortega RA, Carter ES, Ortega AE (2016) Nylon 6,6 nonwoven fabric separates oil contaminates from oil-in-water emulsions. PLoS ONE 11:e0158493

40. Perkas N, Amirian G, Applerot G, Efendiev E, Kaganovskii Y, Ghule AV, Chen BJ, Ling YC, Gedanken A (2008) Depositing silver nanoparticles on/in a glass slide by the sonochemical method. Nanotechnology 19:435604

41. Pol VG, Srivastava DN, Palchik O, Palchik V, Slifkin MA, Weiss AM, Gedanken A (2002) Sonochemical deposition of silver nanoparticles on silica spheres. Langmuir 18:3352-3357

42. Qing Y, Cheng L, Li R, Liu G, Zhang Y, Tang X, Wang J, Liu H, Qin $Y$ (2018) Potential antibacterial mechanism of silver nanoparticles and the optimization of orthopedic implants by advanced modification technologies. Int J Nanomed 13:3311-3327

43. Rai M, Kon K (2015) Nanotechnology in diagnosis, treatment and prophylaxis of infectious diseases, 1 st edn. Academic Press, Boston, pp 191-216

44. Raja S, Ramesh V, Thivaharan V (2017) Green biosynthesis of silver nanoparticles using Calliandra haematocephala leaf extract, their antibacterial activity and hydrogen peroxide sensing capability. Arab J Chem 10:253-261

45. Rajeshkuma S (2016) Synthesis of silver nanoparticles using fresh bark of Pongamia pinnata and characterization of its antibacterial activity against gram positive and gram negative pathogens. Resour Eff Technol 2:30-35

46. Raza ZA, Rehman A, Mohsin M, Bajwa SZ, Anwar F, Naeem A, Ahmad N (2015) Development of antibacterial cellulosic fabric via clean impregnation of silver nanoparticles. J Clean Prod 101:377-386

47. Rivero PJ, Goicoechea J, Urrutia A, Matias IR, Arregui FJ (2013) Multicolor layer-by-layer films using weak polyelectrolyte assisted synthesis of silver nanoparticles. Nanoscale Res Lett 8:438

48. Rivero PJ, Urrutia A, Goicoechea J, Arregui FJ (2015) Nanomaterials for functional textiles and fibers. Nanoscale Res Lett 10:501

49. Shateri-Khalilabad M, Yazdanshenas ME, Etemadifar A (2017) Fabricating multifunctional silver nanoparticles-coated cotton fabric. Arab J Chem 10:S2355-S2362

50. Silhavy TJ, Kahne D, Walker S (2010) The bacterial cell envelope. Cold Spring Harb Perspect Biol 2:a000414

51. Simončič $B$, Klemenčič D (2016) Preparation and performance of silver as an antimicrobial agent for textiles: a review. Text Res J 86:210-223

52. Slavin YN, Asnis J, Häfeli UO, Bach H (2017) Metal nanoparticles: understanding the mechanisms behind antibacterial activity. Nanotechnol Sci Appl 10:115-121

53. Sood A, Granick MS, Tomaselli NL (2014) Wound dressings and comparative effectiveness data. Adv Wound Care 3:511-529

54. Sun X, Shi J, Zou X, Wang C, Yang Y, Zhang H (2016) Silver nanoparticles interact with the cell membrane and increase endothelial permeability by promoting VE-cadherin internalization. J Hazard Mater 317:570-578

55. Syafiuddin A, Fulazzaky MA, Salmiati S, Kueh ABH, Fulazzaky M, Salim MR (2020) Silver nanoparticles adsorption by the synthetic and natural adsorbent materials: an exclusive review. Nanotechnol Environ Eng 5:1

56. Syafiuddin A, Salim MR, Kueh ABH, Hadibarata T, Nur H (2017) A review of silver nanoparticles: research trends, global consumption, synthesis, properties, and future challenges. J Chin Chem Soc 64:732-756

57. Tripathi DK, Tripathi A, Shweta S, Singh Y, Vishwakarma K, Yadav G, Sharma S, Singh VK, Mishra RK, Upadhyay RG, Dubey NK, Lee Y, Chauhan DK (2017) Uptake, accumulation and toxicity of silver nanoparticle in autotrophic plants, and heterotrophic microbes: a concentric review. Front Microbiol 8:07

58. Turner RD, Hurd AF, Cadby A, Hobbs JK, Foster SJ (2013) Cell wall elongation mode in Gram-negative bacteria is determined by peptidoglycan architecture. Nat Commun 4:1496

59. Varadavenkatesan T, Selvaraj R, Vinayagam R (2019) Dye degradation and antibacterial activity of green synthesized silver nanoparticles using Ipomoea digitata Linn. flower extract. Int J Environ Sci Technol 16:2395-2404

60. Varadavenkatesan T, Vinayagam R, Selvaraj R (2017) Structural characterization of silver nanoparticles phyto-mediated by a plant waste, seed hull of Vigna mungo and their biological applications. J Mol Struct 1147:629-635

61. Vinayagam R, Varadavenkatesan T, Selvaraj R (2018) Green synthesis, structural characterization, and catalytic activity of silver nanoparticles stabilized with Bridelia retusa leaf extract. Green Process Synth 7:30-37

62. Wang J, Liu W, Li H, Wang H, Wang Z, Zhou W, Liu H (2013) Preparation of cellulose fiber- $-\mathrm{TiO}_{2}$ nanobelt-silver nanoparticle hierarchically structured hybrid paper and its photocatalytic and antibacterial properties. Chem Eng J 228:272-280

63. Yadav P, Manjunath H, Selvaraj R (2019) Antibacterial and dye degradation potential of zero-valent silver nanoparticles synthesised using the leaf extract of Spondias dulcis. IET Nanobiotechnol 13:84-89

64. Yu K, Lu F, Li Q, Chen H, Lu B, Liu J, Li Z, Dai F, Wu D, Lan G (2017) In situ assembly of Ag nanoparticles (AgNPs) on porous silkworm cocoon-based wound film: enhanced antimicrobial and wound healing activity. Sci Rep 7:2107

65. Zakaria ZA, Mahmood ND, Omar MH, Taher M, Basir R (2019) Methanol extract of Muntingia calabura leaves attenuates $\mathrm{CCl}_{4}$-induced liver injury: possible synergistic action of flavonoids and volatile bioactive compounds on endogenous defence system. Pharm Biol 57:335-344

66. Zhang S, Tang Y, Vlahovic B (2016) A review on preparation and applications of silver-containing nanofibers. Nanoscale Res Lett $11: 80$

Publisher's Note Springer Nature remains neutral with regard to jurisdictional claims in published maps and institutional affiliations. 